International Journal of Linguistics, Literature and Translation

ISSN: 2617-0299 (Online); ISSN: 2708-0099 (Print)

DOI: $10.32996 / \mathrm{ijllt}$

Journal Homepage: www.al-kindipublisher.com/index.php/ijltt

IJLLT

\title{
On the Untranslatability of Cultural Aspects of Myth: An Investigation of Tolkien's The Lord of the Rings
}

\author{
Bahar Bahmani \\ Ph.D., Islamic Azad University, Science \& Research Branch, Tehran. Iran
}

$\square$ Corresponding Author: Bahar Bahmani, E-mail: bahmanikomasi@gmail.com

\begin{tabular}{|c|c|}
\hline ARTICLE INFORMATION & ABSTRACT \\
\hline Received: 17 September 2021 & This study aims to explore the strategies which Persian translators of English myth \\
\hline Accepted: 14 October 2021 & works have adopted in dealing with cultural aspects. In addition, this study scrutinizes \\
\hline Published: 31 October 2021 & the culture-related problems which have led to untranslatability in myth translation. \\
\hline DOI: $10.32996 / i j l l t .2021 .4 .10 .27$ & $\begin{array}{l}\text { The analyzed parts were extracted from the first book of The Lord of the Rings (2012) } \\
\text { by Tolkien and its two Persian translations by Alizadeh (2003) and Amini (2004). This }\end{array}$ \\
\hline KEYWORDS & comparative analysis was done based on the characteristics of adequate translation \\
\hline $\begin{array}{l}\text { Translation, translatable, } \\
\text { untranslatable, myth, cultural } \\
\text { differences }\end{array}$ & $\begin{array}{l}\text { proposed by Newmark (1998) and Baker (1992), and also adequate discoursal } \\
\text { translation components proposed by Lotfipour (2015). The most attention is on the } \\
\text { translating of proper names, the genre of the work, and the author's style about the } \\
\text { cultural dimension of the work. The results revealed that the cultural knowledge of the } \\
\text { translator about myth, origins, and features, affects the adequacy of translation. In } \\
\text { addition, the main finding of this study proved that certain factors influence the } \\
\text { translator's performance to produce an adequate myth translation. }\end{array}$ \\
\hline
\end{tabular}

\section{Introduction}

Literature is representative of a nation's culture and, it is the culture that determines the motifs and beliefs behind the literature and myth of a society. Due to the vast scope of differences between cultures, there are barriers and problems during the process of translation that some of them may even lead to untranslatability. In translating myth works, especially Norse myth, motifs, and cultural issues are very different from their Persian counterparts.

The Lord of the Rings is embellished with cultural aspects of Christian and Norse mythology. The genre of this narration, its author's style and the proper names, and the language coined by the author are among those aspects that make this work cultural, and controversial for translating. The purpose of this study is to assess the available Persian translations of The Lord of the Rings and find out whether the translators can hold the cultural framework or not. To evaluate the faithfulness of the translators to the original meaning for rendering to SL readers, and the adequacy of the target text would be the most significant endeavor of the researcher.

\subsection{Tolkien and The Lord of the Rings}

John Ronald Reuel Tolkien (1892- 1973), an English philologist, a university professor, an author, and a devout Roman Catholic, has been considered the master of creating ancient mythical worlds. The success and influence of his works brought him popularity and identified him as the father of modern fantasy literature. The Lord of the Rings is written in one thousand pages in three volumes entitled The Fellowship of the Ring, The Two Towers, and The Return of the King. The books were written during World War II, and published in 1954-55. They have been reprinted several times and translated into many different languages. According to many critics, it is one of the most popular and influential works in 20th-century literature. It also has been adapted for film, radio, and stage several times.

Compared to Tolkien's other works, the story of The Lord of the Rings is developed into a long, dark, and serious plot in writing and style; therefore, it addresses older audiences. This tale grew in the telling until it became a history of the Great War of the Ring and included many glimpses of the yet more ancient history that precede it (Tolkien, 2012, p. 6). The genre of the story is a

Copyright: (c) 2021 the Author(s). This article is an open access article distributed under the terms and conditions of the Creative Commons Attribution (CC-BY) 4.0 license (https://creativecommons.org/licenses/by/4.0/). Published by Al-Kindi Centre for Research and Development, London, United Kingdom. 
controversial subject. Many critics declared different views about the genre of the novel, but Tolkien stated that The Lord of the Rings is a myth, a story full of symbols.

Reza Alizadeh translated the whole novel into Persian in 2002. It was published firstly under the title of فرمانرواى حلقه 2003 then the publisher changed the name of the book into ارباب حلقه ها in the reprinted versions. Alizadeh's translation was reprinted as the best seller translation of the trilogy in Iran.

Another Persian translator, Parviz Amini, translated the novel in 2004. This translation never gained the acceptability and success of Alizadeh's translation despite the translator's efforts and different approaches for translating the work.

\subsection{Translation and Literature}

High-valued and well-established hierarchies, that is poetry, drama, and prose, as Baker (1992) stated, are known as literature. When it comes to translating these hierarchies, they are considered worthy of being rendered, but transferring them to another langue and culture is not an easy task. Literary translation is considerable because of different reasons. As we know, there are various forms to express a meaning even within one language. Only when a form is being used in its primary meaning or function is there a one-to-one correlation between form and meaning (Larsen, 1998). In literature, the diversity of meaning or the lack of exact correlation and figurative means make the task of literary translation significant. Thus, this kind of translation is recognized as a dynamic and problematic process of translation in culture-bound discourse that needs attention both in linguistic and cultural aspects. During translating a literary work, some factors cause to misinterpret of the authors or devalue their literary works; such as lack of adequate knowledge and prejudice of translators.

A literary translator should know both source language and culture and also target language and culture completely. As Larsen (1998), stated that two criteria are necessary to produce a good translation: an adequate knowledge of the SL and an adequate command of the language into which one is translating that is TL. Literary translators not only should attempt to render the original meaning, but also they have to transfer it to the target audience correctly.

If literary translators do not know the cultural biases of TL, they will not produce qualified work. Baker (2006), stated, the translators' task is to create new work in the target language and literature. Baker added that literary translation is a social and cultural bound process in which the translator plays a significant role in these complex interactions (ibid).

\subsection{Translation and culture}

The translation is inevitable to communicate inter-culturally and inter-lingually. Newmark (1998), defined culture as the way of life and its manifestations that are peculiar to a community that uses a particular language as its means of expression. Thus, each language group has its own culturally specific features.

Since the cultural meanings are steeped in the language, the knowledge and ability of the translator are significant to capture the cultural concepts and cast them in the target text. A translator should be aware of the two cultures to understand the original meaning and transfer it within the counterparts of the target culture and language.

Toury (2012), stated translation is a kind of activity that inevitably involves at least two languages and two cultural traditions. It implies that translation is a communicative process, communication between nations' languages and cultures.

\subsection{Myth Translation and Untranslatability}

Myths present the spiritual or religious life aspects of a nation. They refer to the symbolic beliefs of a typical society in history. Therefore, they are considered complex cultural phenomena.

Newmark (1991), pointed out that a word is essentially a cultural memory in which the historical experience of the society is embedded. Therefore, in the myth which embodied the related historical and cultural features of a nation, transferring the lexical and symbolic structures of the original text is considerable.

For instance, in the process of translating a Greek mythic novel into Persian, the translator is faced with two main challenges: firstly, $\mathrm{s} /$ he should deal with the concept and lexicon in $\mathrm{SL}$, which require an understanding of Greek culture and mythology, and secondly, the translator should take TL meaning equivalent of an item in $\mathrm{SL}$, include features absent in TL culture. Thus, myth translation does not have the problem of finding just equivalent but interpreting a text encoded in a semiotic system. In The Lord of the Rings, a Norse myth, the case study of the present research, verbal or even linguistics equivalents do not provide the TL community with an adequate translation due to the significant differences between Norse culture and Persian culture.

Utilizing cultural equivalents requires knowing the differences and similarities between the cultures and cultural implications. The choices made by the translators as the decision whether to keep stylistic features of the source language text or whether to keep 
the figurative language of the original become considerable in the case of myth translation. In The Lord of the Rings, the evil powers, for instance, are specified as posterities of Tolkien's Satan, which are impossible or implausible to render in a current interpretation but in a Christian interpretation.

The untranslatability always exists in a myth text since its features are rooted in the culture and language. The more differences between SL and TL, the more untranslatable aspects occur. Therefore, untranslatability happens when the translator translates the cultural concepts to the SL while there is no equivalent cultural issue in the TL.

Lotfipour (2015), stated that translation of literary discourse in the sense of exact meaning transferring and effect of author's cultural intention was really testing or even impossible. He believed that cultural factors always become a barrier in translation, and often the translators face untranslatability.

\section{Statement of the problem}

Myths transfer a message linked to the religious, spiritual, and cultural life of typical society. Tolkien, as a contemporary mythmaker, has his style of creating a myth. He was a linguist and a philologist before he was an author. The Lord of the Rings is full of Catholic imaginations steeped in Western culture.

Related themes of Christian culture such as the Fall, Sin, Guilt, Redemption, Forgiveness, the battle against Evil, and Grace have filled the whole story. In addition, mythic characters of western and especially Norse mythology are the main characters of the story. Different creatures as Orcs, Elves, Wizards, and Hobbits are Tolkien's most important protagonists and antagonists. A Persian translator who is not acquainted with these fictional races would encounter difficulties and barriers in rendering due to the differences between Persian and Islamic beliefs, fairy tales, mythic characters, and Norse and Christian mythology.

Besides, Tolkien has his style of writing. Speech style, symbolic use of language, character description, environmental vision, narration, and archaic use of language are some stylistic manners that differentiate him from other authors and make him a unique myth and fantasy author of his time. The complex issues, such as the author's style and cultural themes of the novel, are among those criteria that create the main barriers leading to difficulties and untranslatability.

The goal of the literary translation is to induct the sensibilities and effects of the source text to the TL readers. Cultural features, religious concepts, and the specific style of the author make The Lord of the Rings hard or even impossible to translate and transfer into another culture and language.

Therefore, the raised questions around this study include:

1- Does knowledge of cultural aspects of a mythic novel, particularly the knowledge concerning genre, style, and proper names, significantly affect the adequacy of the translation?

2- Does inadequate cultural knowledge of two languages lead to the untranslatability of mythic novels?

\section{Translation Theories}

\subsection{Peter Newmark (1916-2011)}

Newmark defined two types of translation, Communicative and Semantic translation. He stated that semantic translation applies to translate the texts in which the exact words of the author are important: such as religious, philosophical, political, scientific, technical texts, autobiographies, and quotations. According to Newmark (1998), the literary translator is on a tightrope and has to work so carefully. His first loyalty is to his author; his second is to the target language, his last to the reader.

Communicative translation for Newmark is smooth, simple, clear, direct, conventional, compatible with a particular register of language, and contains more generic words; While, semantic translation is complex, awkward, detailed, specific, and concerned with the thought process. Newmark (1998), believed that a message can be transferred by semantic method, communicative method, or a combination of these methods.

He stressed that the accuracy and ability to reproduce the most possible of the original meaning is the main task of the translator. Therefore, the translator of myth should consider the intended message, its value, and significance to the author and reader, the symbolic characteristics, and employ an appropriate approach to transfer the meaning and style in the best way.

\subsection{Mona Baker (1953-)}

M. Baker offered a specific list of conditions at different levels concerning the translation process in which the notion of equivalence is definable. Baker combined the linguistic and communicative approach and distinguished between four types of equivalences. 
The first type is the equivalence at the word level and above word level. When the translator analyzes the SL text, s/he observes the words as single units to find a counterpart or equivalent term in TL. It means that the translator should pay attention to several factors when considering a single word, such as number, gender, and tense (Baker, 1992).

The second type is the grammatical equivalence that refers to the diversity of grammatical categories across languages, about which Baker (1992), stated that grammatical rules may vary across languages and this may pose some problems in terms of finding a direct correspondence in the TL.

Baker's third type of equivalence is textual equivalence. It is the equivalence between an SL text and a TL text in terms of information and cohesion. Considering texture is significant during the translation because it provides guidelines to comprehend and explore the SL text. It can help the translator produce a cohesive and coherent text for the target audience in a specific context. The translator's task is to maintain the cohesion and coherence of the SL text for the target reader. Three main factors guide the decision of the translator: the target audience, the purpose of the translation, and the text type (Baker,1992, p.200). For instance, regarding The Lord of the Rings, Tolkien's audience is adults. Therefore, the translator's choice of equivalence should be in a way to satisfy these audiences in the target context.

Baker (1992), defined coherence as a network of relations that organize and create a text. For her Cohesion is the network of surface relations that link words and expression in a text, and Coherence is the network of conceptual relations that underlie the surface text (ibid). Implicatures are aspects of meaning which are over and above the literal and conventional meaning of an utterance and they depend for their interpretation on a recognition of the Co-operative Principle and its maxims (Baker, 1992, p.227).

The last type of Baker's equivalence, which is related to the topic of this study, is pragmatic equivalence. She defined (1992), pragmatics as the study of language in use. It is the study of meaning, not as generated by the linguistic system but as conveyed and manipulated by participants in a communicative situation. Coherence and implicature is the answer of Baker to the question of how a given text comes to make sense to a given readership? She believed to find the meaning particularly, culture-based meaning we should venture beyond the textual level of connecting sentences and paragraphs together and identifying various textual features (ibid).

According to Baker (1992), if we do not understand the meanings of the words and structures used in a text, we cannot work out its implied meanings. Knowledge of the language system may not be sufficient but it is essential if one is to understand what is going on in any kind of verbal communication. This means that any mistranslation of words and structures in the source text may well affect the calculability of implicatures in the target text.

Therefore, the translator needs to explore the implied meaning in the source text. In the case of myth translation, the lack of knowledge about the implied meaning of the text and some complicated linguistic and cultural issues can lead to the incalculable or inadequacy of expressing the main idea or tone.

\subsection{Kazem Lotfipour (1955 -)}

Vocabulary, structure, texture, degree of indirection, language variety, cognitive effect, and aesthetic effect are seven components were listed by Lotifpour to consider in the translation equivalence definition.

Lotfipour (1990), considered the text as an interface between the sender and receiver. He believed that text acts as a mediator between the producer and the receiver (ibid). He discussed that since different languages vary in structure, the translator should not expect to replace all the SL text subsystems with those TL text subsystems.

Regarding the literary and myth translation, the translator should be faithful to the source text and transfer the original style and intended meaning adequately and faithfully. Therefore, according to Lotfipour (2015), the translator should operate within the overall discourse framework trying to convey the communicative values of the SL author by employing strategies to find the equivalents in the TL discourse.

Furthermore, Lotfipour (1990), discussed attaining a satisfying translation. The seven above-mentioned components should take into account in determining SL equivalences. Below some of them are explained briefly:

\subsubsection{Vocabulary}

A translator should consider all of the likely meanings reflected in the SL lexical item in determining the target language equivalents. They include denotative, stylistic, collective, contrastive, reflected, implicative, and figurative aspects. In myth 
translation or generally literary translation, the translator must be aware of the relationship between the lexical forms and their meaning which might vary across languages. Thus, different languages may employ different strategies for lexicalizing the same mean. The translator should take the substance of the meaning and consider how it can be lexicalized within the TL lexical structure to attain the original meaning intended by the author.

\subsubsection{Structure}

The structure-for-structure translation is replacing SL structural elements with its parallel form in TL. Lotfipour (1990), stated because languages differ in their structural or grammatical forms and their communicative values, the translator should avoid the structure for structure translation. For him translating the literary texts, particularly the mythic texts, from English to Persian, structure-for-structure translation would not be acceptable because of differences between the languages and their forms (ibid).

\subsubsection{Language variety}

Language varieties reflect different features, such as social and interpersonal ones. They contain impressive factors that should be considered in translating process. In translating mythic stories, they are considerable because they determine which strategy should be applied by the translator to transfer them. The translator should maintain the SL variety in $\mathrm{TL}$; by considering the texulaization differences in languages.

\subsubsection{Aesthetic effect}

Lotfipour (1990), stated the translator should transfer the impression of the original text on the reader to TL reader. Tolkien's myth intended to affect the audience with its language and plot employing particular wording, coined names, and mythic and heroic themes.

In his article Discourse Analysis and the Problem of Translation, Lotfipour (1990), presented the aspects of textual indices and dimensions of discourse as two factors to be considered in translation. For him, textual indices include the strategies that have been employed in the SL text. He stated that not a single move in the SL text can be ignored in the translation process.

He (1990), defined translation from a discoursal view as an attempt of the translator to create the conditions in which the TL reader can interact with the SL author. It might be the same textual indices not presented in all languages, but there is a parallel relationship between the textual indices and their discourse function. Loftipour believed translation is not replacing SL text through TL textual resources.

Consequently, Lotfipour and other translation scholars agree that different languages are different in many aspects. Myth and generally literature are rooted in the nation's linguistic and cultural background. Accordingly, translating in such a field requires adequate knowledge in both language and culture to render the intended meaning and style of the ST to the target reader.

\section{Data Analysis}

\subsection{Translation of Genre: Myth and Fantasy}

As Trosborg (1997), stated that lack of relevant knowledge of the genre, communicative functions, text types, and culture may result in distorted translations. Translators must be familiar with the rhetorical and textual conventions of genres both in the source- and the target language - the two code systems - to realize the communicative aim of the translation, and to be able to produce texts that are acceptable by the professional community.

In myth translation, the subject of this study, certain motifs, and cultural issues have been embodied on the source text which is very different from their Persian counterparts. Establishing adequate and correct translation equivalence, in this case, is of utmost importance for the translators of this genre. As discussed before, in the case of cultural translation of mythic novels, translation equivalence should be in a way that creates the same effect and situation as in SL text.

The Lord of the Rings, a combination of different genres, has raised considerable debates between the critics. Some critics claim that it belongs to the sorcery genre. Other critics regard it as high fantasy, adventure epic, or heroic romance. Tolkien asserted that The Lord of the Rings is a myth, a story with various symbols.

Finally, the translator needs to be aware of the textual conventions of the genre, as the validity of translated different genres might depend on the expression of a specific style.

Moving constantly in and out of his talk was Old Man Willow and Frodo learned now enough to content him, intended more than enough, for it was not comfortable lore (p.142).

$$
\begin{aligned}
& \text { رضا عليزاده: يد-مرد بيسر دائم در گفته هاى او حاضر مى شد و از آن بيرون مى رفت. و فرودو آن قدر خيزها درباره او دانست كه راضى }
\end{aligned}
$$

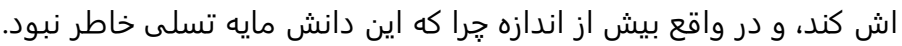




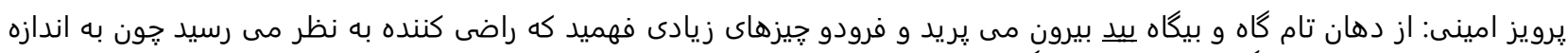

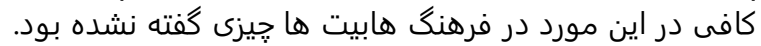

"Old Man Willow" was a willow in the "Old Forest". He had under his control all of the trees in the "Old Forest". He was not a common willow. An evil power inside him and he cast spells on people passing their way inside the old forest. Therefore, its name should indicate his nature, and the word willow alone is not enough to act so. "بيد-مرد پير Alizadeh's translation is an adequate equivalent in this case.

According to Lotfipour (2015), the words' figurative meaning is one of their considerable characteristics that should be taken into account during the equivalence. The genre of this work is a myth, and myths are always full of creatures that are related to the culture and history, from which they originate. In Norse mythology, the lore about ancient creatures like moving trees is quite familiar. A translator, in this case, must find out the truth and belief about these creatures and maintain their equivalents in different cultures. In the process of treating Tolkien's complex terminology of mythic creatures, the translators should apply adequate strategies for translating some names, modifying others, and leaving some in their original forms. But in the two above-cited translations, none of the translators has privileged the practical guideline of Tolkien to translate names in The Lord of the Rings.

\subsection{Translation of Cultural Concepts and Tolkien's Style}

As mentioned previously, myths are rooted in the spiritual or religious life of a nation. They refer to the notions of belief of typical society. Therefore, they are considered a complex cultural phenomenon. According to Baker (1992), lexical items which contain culture-specific concepts create problems in translation due to unknown or non-equivalent concepts in the target language. Therefore, the risk of untranslatability is always for the elements of the mythic text, which are cultural and linguistic bound. The larger differences between SL and TL in their language and culture, the more untranslatable aspects occur.

Tolkien's style, diction, and expressions that transfer his intended meaning to the reader are rooted in cultural aspects of his mythic narration. For example, Tolkien's style for describing his protagonists, their way of life and speech, their setting of life, and their characteristics are cultural concepts. Also, as Lotfipour (2003), stated that cognitive effect factor related to the style should be preserved in the translation process.

Additionally, the theme is the underlying and implicit meaning or concept embedded in the narration. Tolkien's works all have their own specific styles and themes. The Hobbit was written in the fairy-tale form but The Lord of the Rings has a darker tone. It narrates a quest and introduces ethics and sacrifice. In The Lord of the Rings, Tolkien's narrative techniques take the hero from the cycle of the events and lead to sacrificial death essentially. Its somber tone is appropriate to the inevitable decline and death story. The theme of The Lord of the Rings is the unending struggle of good and evil.

At that time Frodo was still in his tweens as the hobbits called the irresponsible twenties between childhood and coming of age at thirty-three (p.47).

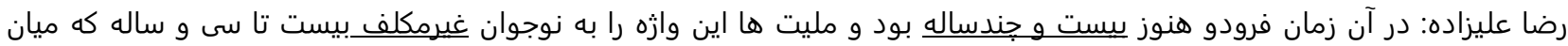
كودكى و سن بلوغ قرار داشتند، اطون فرون إن كردند.

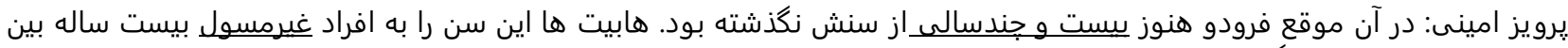

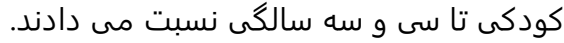

Here Tolkien introduced Frodo Baggins, Bilbo's niece, and his social age rank within his society. By 'tweens' Tolkien meant a Hobbit between his childhood and 33 who is irresponsible for the social acts. Both translations are culturally adequate. In the extracted example the word irresponsible was translated into two different equivalents غيرمسول and غيرمكلف The first one conveys a more religious-cultural meaning than the second one based on what Tolkien intended.

\subsection{Translation of Culture Related Titles and Names}

By innovating the proper names and titles in The Lord of the Rings, Tolkien focused directly on Anglo-Saxon culture. Most of the proper names in the novel are Old English words or combinations of them which have roots in Old Norse and Anglo-Saxon culture and traditions. Each of these names carries a symbolic meaning and history behind it. That's why Tolkien wrote a guideline for the translators of his book to assist them in translating names. In this guideline, there is a list of the proper names that give the translator hint to render them based on the criteria. Concerning the proper names of people and places Tolkien said:

All names not in the following list should be left entirely unchanged in any language used in translation, except in lexical $-s$, -es should be rendered according to the grammar of the language. Names that are given in modern English represent names in the Common Speech, often but not always being translations of older names in other languages. The language

Page | 228 
of translation now replaces English as the equivalent of the Common Speech; the names in English form should therefore be translated into the other language according to their meaning as closely as possible (Lodbell, 1975).

The Shiriffs was the name that the Hobbits gave to their police or the nearest equivalent that they possessed. (p.15).

رضا عليزاده: داروغكان نامى بود كه هابيت ها به يِيس يا نزديكترين معادل براى آن خيزى كه به عنوان پِليس داشتند اطلاق مى

كردند.

يرويز امينى: هابيت ها به نكهبانان، شيريف مى گفتند.

Tolkien described the "shirrifs" as an obsolete form of the English word "sheriff". Here it means Shire-officer, and Tolkien intended to make the connection to the Shire. He stated that 'Shirriff' and 'Shire' are supposed to be special Hobbit words, not generally current in the Common Speech of the time; it was derived from the former language related to the Rohirrim. Therefore, it is considered as a part of common speech but a local word. So Tolkien (2012, third section, para 2), suggested that it is not necessary to translate it or do more than accommodate its spelling to the style of the language of translation. The first translator has coined a new word داروغكان for it, but the second translator made equivalence to what Tolkien intended by changing the spelling of the word and preserving its original shape.

\section{Findings}

According to the findings of the present study, two translation procedures are applied to transfer the mythic work and its cultural aspects in TL. In the first procedure, the translator gives a clear image from the SL statutes of the novel to the TL readers. Lotfipour (1990), defined this as the translator's attempt to create the condition in which the TL reader can interact with the SL author.

In the second one, the translator can produce the target text, as a writer produce the original text, manipulate it by own taste and style so that the SL material would be conveyed to the TL readers, so they accept it as an original work.

In this study, the main focus was on culture-related problems of translating the myths, and it was found that the lack of cultural knowledge of translators about myths affects the adequacy of translation.

The data analysis reveals that both analyzed Persian translations made countless mistakes and failed to convey the original meaning; because the translators did not understand it correctly, and in some cases, they did not have enough knowledge of the complicated linguistic and cultural background about the world depicted by Tolkien. Sometimes the main idea is lost, and the conveyed meaning is different from the original.

\section{Conclusion}

\subsection{Overview}

The function of translation as a mediator in cross-cultural communication is to introduce one culture to another. Cultural aspects always have been the obstacle against translation procedures. Sometimes these obstacles result in untranslatability during the process of cross-cultural communication and translation. Myths are considered one of the most important literary genres by many literary critics. Scholars define myths are tales believed as true, usually sacred, which set in the distant past or other worlds with extra-human, inhuman, or heroic characters.

The Lord of the Rings has been one of the most famous narrations which hold a mythical tone. The popularity of the work has led to numerous translations in many languages all over the world. Facing an epic myth filled with cultural concepts, the translators as the message conveyors should try to create a product adequate both in content and effect. Untranslatability is the result of cultural gap and cultural differences between English and Persian language, literature, and mythology that needs to be avoided as much as possible.

By analyzing and comparing two translated versions of The Lord of the Rings with its original version, this study aimed to discover the culture-related problematic areas of mythology that have led to untranslatability. It also detected the strategies used by the translators of the work. Finally, this study aimed to suggest the best solution for culture-related problems of translating myth.

\subsection{Conclusion}

The enduring popularity of The Lord of the Rings has encouraged the different translators to translate the work as successfully as possible. In Iran, in the lens of the translation critics and the audiences, the translation done by Alizadeh (2002) is relatively sufficient and understandable, but it is not a completely adequate translation. Sometimes the central idea or feeling is lost regarding the 
cultural issues and aspects. Also, some parts remained untranslated, which the aim of this study appertained to analyze. The innovative language, Tolkien's style of description, and his proper names for places and characters are negotiating points.

Studying the material within the mentioned theoretical framework revealed two translation procedures were employed to render this mythic work and its cultural aspects into Persian. In the first procedure, the translator brings a copy and clear picture of the SL circumstances to TL readers, keeping strictly to the original. Lotfipour (2007), defined this as an attempt of the translator to create the conditions in which the TL reader can interact with the SL author. While in another translation, Amini (2003) treated the target text as a writer treats his material to produce a text, so the translator brought closer the material to TL readers, who accept it as an original work. Lotfipour (2007), believed that translation of literary discourses in the sense of exact meaning transferring and effect of author's cultural intention was really or even impossible.

The main focus, in this study, was on the problems which a translator faces in translating the cultural concepts of myths, and considering the significance of cultural knowledge about myths whether impacts the adequacy of a translation or not. According to the findings, certain factors affect the adequacy of the translation and the cultural impact of the SL myth on TL readers. They include background knowledge of TL readers about the SL novel and its social, historical, and geographical characteristics in addition to the translator's knowledge about them in the SL context.

Adequate knowledge about these factors directly affects the quality of the product of the myth translation procedure. The mentioned factors determine the measure of translatability in the SL text. Often untranslatability is a result of a cultural gap or cultural unawareness. But according to the mentioned factors, it can always be compensated to a certain degree but not eliminated. In the case of The Lord of the Rings, a translator can avoid untranslatability employing referring to the history and characteristics of Norse mythology, Tolkien's guidelines, his other related books, letters, and the preface of the novel written by him.

Therefore, concerning the first research question, it is concluded that the background knowledge of the translator, cultural and historical, significantly affects the adequacy of the translation. Additionally, the background knowledge of the TL readers about the social, historical, and geographical characteristics of the novel, would impact the understanding of the mythic novel.

Concerning the second research question, in the case of mythic cultural aspects, it is concluded that untranslatability always is the result of cultural gaps or lack of cultural knowledge. In the case of The Lord of the Rings, the translator can prevent untranslatability by referring to Norse mythology, Tolkien's guidelines, his other related books, letters, and the preface of the novel written by him.

Thus, it is deduced that on one side, inadequate cultural knowledge, and on the other side, the cultural gap between English and Persian leads to untranslatability and inadequacy of translation in the case of mythic novels. But the translator can compensate for this gap by studying more about the background of the original text.

\subsection{Pedagogical implications}

First of all, the findings of this study inform translation scholars and translators of the effects of cultural gaps and differences on the process of translation. Also, translation scholars and translators can get benefit from the results and recognize how background knowledge and other issues suggested in this study can improve the adequacy of their work. Finally, this study shows that how adequate cultural and linguistic knowledge of translators is significant to avoid untranslatability.

\subsection{Suggestions for further studies}

The researchers are suggested to study the other aspects of the field as other genres of literature like poetry, fantasy, or legends. The focus of this study is on the culture-related problems of translation. Thus the study topic can be replicated based on other problematic areas of translation such as linguistics or terminology.

This study analyzed Tolkien's popular work The Lord of the Rings, but there are so many other modern myth examples that can be analyzed to see if the results are the same or not. The Lord of the Rings is published in three volumes and six books. The case study of the present study covered the first book, other investigations can be made about the other volumes of the novel to ensure that the same results are inferred.

\section{References}

[1] Baker, M. (2018). In other words: A coursebook on translation. Routledge.

[2] Balogh, D. (2019). The role of genres and text selection in legal translator training. Studies in Logic, Grammar and Rhetoric, 58(1), 17-34.

[3] Camps, A. (2007). BAKER, Mona. 2006. Translation and Conflict. A Narrative Account. Transfer, 2(2), $72-74$.

[4] Herman, T. (1985). The Manipulation of Literature. Routledge.

[5] Lobdell, J. (1975). A. Tolkien Compass: Including J. R. R. Tolkien's Guide to the Names in The Lord of the Rings. Open Court Pub Co. 
[6] Lotfipour-Saedi, K. (2015). Suggestions toward Some Discourse-Analytic Approaches to Text Difficulty: With Special Reference to" T-Unit Configuration" in the Textual Unfolding. Iranian Journal of Language Teaching Research, 3(1), 1-18.

[7] LOTFIPOUR, S. K., \& MOGHADDASSI-SARABI, S. H. (2004). Lexical Chains, their discoursal values and cognitive effects.

[8] Lotfipour-Saedi, K. (1990). Discourse analysis and the problem of translation equivalence. Meta: journal des traducteurs/Meta: Translators' Journal, 35(2), 389-397.

[9] Munday, J., \& Zhang, M. (Eds.). (2017). Discourse analysis in translation studies (Vol. 94). John Benjamins Publishing Company.

[10] Newmark, P. (1988). A textbook of translation (Vol. 66). New York: Prentice hall.

[11] Newmark, P. (1993). Paragraph on translation (p. 19). Clevedon: Multilingual Matters Ltd.

[12] Newmark, P. (1991). About translation (Vol. 74). Multilingual matters.

[13] Tolkien, J. R. R. (2012). The Fellowship of the Ring: Vol.1. The Lord of the Rings. Allen \& Unwin.

[14] Tolkien, J. R. R. (2012). The Return of the King: Vol.3, The Lord of the Rings. Allen \& Unwin.

[15] Trosborg, A. (1997). Text Typology and Translation. Benjamin Publishing Company.

[16] Wechsler, R. (1998). Performing Without A Stage: The Art Of Literary Translation. Catbird Press.

عليزاده، رضا. (1382). فرمانرواى حلقه ها: ياران حلقه، ته [18] 